\title{
Effect of Thermal Annealing on the Electrochemical Capacitive Performance of Reduced Microcrystalline Graphene Oxide
}

\author{
Yun Lei , Zheng Zhang, Chengyi Fang, Xin Bing
}

School of Resources and Environmental Engineering, Wuhan University of Technology, Wuhan, 430070

*E-mail: leiyun@whut.edu.cn

doi: $10.20964 / 2017.10 .26$

Received: 9 June 2017 / Accepted: 3 August 2017 / Published: 12 September 2017

\begin{abstract}
Microcrystalline graphene oxide (MGO) was reduced by thermal annealing to prepare reduced microcrystalline graphene oxide (RMGO). The produced RMGO was characterized by X-ray diffraction, ultraviolet-visible absorption spectroscopy, Fourier transform infrared spectroscopy and transmission electron microscopy. The results show that the absorption peaks of the oxygen-containing functional groups almost disappear due to the removal of oxygen atoms from the basal plane of graphene oxide in the temperature range of $150-450^{\circ} \mathrm{C}$ in nitrogen. The electrochemical behaviour of RMGO annealed at different temperature was evaluated by three-electrode cyclic voltammetry and electrochemical impedance spectroscopy. The results show that an obvious increase in specific capacitance and decrease in charge-transfer resistance can be observed for RMGO at the annealing temperature of $250^{\circ} \mathrm{C}$.
\end{abstract}

Keywords: microcrystalline graphene oxide; graphene; thermal reduction; electrochemical properties

\section{$\underline{\text { FULL TEXT }}$}

(C) 2017 The Authors. Published by ESG (www.electrochemsci.org). This article is an open access article distributed under the terms and conditions of the Creative Commons Attribution license (http://creativecommons.org/licenses/by/4.0/). 